\title{
Inadequate Breastfeeding may lead to Severe Hypernatremia: A Case Report
}

\author{
Salem Yahyaoui", Sonia Mazigh and Azza Sammoud \\ Department of Pediatrics C, Children Hospital of Tunis, Faculty of Medicine of Tunis, Tunis El Manar University, Tunisia
}

*Corresponding author: Salem Yahyaoui, Department of Pediatrics C, Children Hospital of Tunis, Faculty of Medicine of Tunis, Tunis El Manar University, Tunisia, E-mail: yahyaouisalem@yahoo.fr

Received date: June 21, 2018; Accepted date: July 05, 2018; Published date: July 11, 2018

Copyright: (c) 2018 Yahyaoui S, et al. This is an open-access article distributed under the terms of the Creative Commons Attribution License, which permits unrestricted use, distribution, and reproduction in any medium, provided the original author and source are credited.

Citation: Yahyaoui S, Mazigh S, Sammoud A (2018) Inadequate Breastfeeding leads to Severe Hypernatremia: A Case Report. Crit Care Obst Gyne. Vol.4 No.2:7.

\section{Abstract}

Background: The benefits of breast feeding are well established worldwide. Inadequate breastfeeding may result in severe complications such as hypernatremic dehydration. This condition is rare and not well known. In this case report, we describe a case of severe hypernatremic dehydration revealed by fever with delayed consultation.

Presentation of case: We report the case of an exclusively breastfed male newborn. He was referred on the 13th day of life because of lethargy and fever. He had a severe dehydration on clinical examination. Serum sodium was of $172 \mathrm{mmol} / \mathrm{L}$. The breast milk sodium was high as compared to a volunteer control ( $85 \mathrm{mmol} / \mathrm{L}$ vs $19 \mathrm{mmol} / \mathrm{L}$ ). Breastfeeding was temporarily suspended and reintroduced after 5 days with favorable evolution.

Conclusion: Breast feeding associated hypernatremia can cause life-threatening complications in newborns. Prevention requires frequent and sufficient breastfeeding and weight gain monitoring during the first days of life.

Keywords: Breastfeeding; Dehydration; Hypernatraemia

\section{Introduction}

Breastfeeding is universally recognized as the best and the safest way to feed neonates. However, it has been reported that some healthy breast fed newborns developed hypernatremic dehydration. This condition is rare and not well known especially in developing countries. Hypernatraemia is a serious situation which may cause life threatening complications such as intracerebral edema, haemorrhage, and gangrene $[1,2]$. Mechanisms, risk factors and management of hypernatraemia in breast fed newborns still controversial. This paper describes and discusses a case of hypernatremic dehydration in an exclusively breast fed neonate revealed by fever.

\section{Presentation of case}

We report the case of a 13-day-old male neonate admitted to our Pediatric Department because of lethargy and fever. He was born at full term to a 28-year-old primiparous mother who had no pathological history and had no history of medication. The pregnancy proceeded normally without complications. He was born at 38 weeks of gestation with a birth weight of $3500 \mathrm{gm}$ and an Apgar score of 8 at 1 minute, 9 at 5 minutes and 10 at 10 minutes. There was no context of neonatal infection. He was breastfed every 4 hours. His stool frequency was four bowel movements per day and he had no history of vomiting or regurgitation. At admission, his weight was of 3000 grams. The body temperature was of 38.3 degrees Celsius. The heart rate was of 120 beats per minute. He was lethargic and he had very sunken eyes. The skin pinch gone back very slowly, the anterior fontanel was slightly depressed and the tongue was very dry. Heel-stick glucose was of $0.8 \mathrm{~g} / \mathrm{L}$. There were no other abnormalities on the physical examination. The patient was immediately rehydrated intravenously with $5 \%$ glucose serum containing 2 ampoules of sodium chloride $10 \mathrm{~mL}(10 \%), 2$ ampoules of potassium chloride $10 \mathrm{~mL}(7.4 \%)$ and one ampoule of calcium gluconate per 500 millilitres. Blood tests showed: urea: $18 \mathrm{mmol} / \mathrm{L}$, sodium: $172 \mathrm{mmol} / \mathrm{L}$, potassium: $4.2 \mathrm{mmol} / \mathrm{L}$. Urine sodium was of $18 \mathrm{mmol} / \mathrm{L}$. The Complete blood count was normal. $C$ reactive protein was of $1 \mathrm{~g} / \mathrm{L}$. Serum procalcitonin was $<0.05 \mathrm{ng} / \mathrm{mL}$. Chest and abdominal X-rays were normal. Renal ultrasound showed two kidneys of normal size, regular contours and good differentiation with no dilation of the excretory cavities. The rehydration was slowed down and conducted over 48 hours regarding the situation of hypernatraemia. The baby gradually increased his weight in 3 days with normalization of biological parameters. The transfontanellar ultrasound performed after 4 days of hospitalization was normal. This situation of hypernatraemic dehydration had no obvious cause since the patient had no fluid loss. The urine density was of 1020 (normal=1005 to 1030) and serum Antidiuretic hormone (ADH) level was of $2.1 \mathrm{pg} / \mathrm{mL}$ (normal=1 to $5 \mathrm{pg} / \mathrm{ml}$ ). We then discussed the hypothesis of high breast milk sodium level.

The breast milk sodium dosage was performed on the $13^{\text {th }}$ day of life. The concentration was $85 \mathrm{mmol} / \mathrm{L}$. It was of 19 $\mathrm{mmol} / \mathrm{L}$ in the milk of a volunteer control assessed also on the $13^{\text {th }}$ day post-partum, confirming the diagnosis of 
hypernatremia due to a high breast milk sodium level. The newborn was fed by a powdered infant formula for 5 days while the mother was extracting her breast milk. He was subsequently breast fed after a decrease of the breast milk sodium level to 21 $\mathrm{mmol} / \mathrm{L}$. He was discharged from the hospital after 6 days. Thereafter, he was doing well and his growth was normal without sequelae.

\section{Discussion}

Hypernatraemic dehydration is a rare complication during breastfeeding. It is defined by a sodium level greater than 150 $\mathrm{mmol} / \mathrm{L}$ [3]. The main symptom is weight loss that can range from 5 to $25 \%$ of birth weight associated or not with other clinical signs of dehydration [4-6]. In the presented case, the consultation was motivated mainly by fever and the mother did not pay attention to weight loss. Thereby, our patient had evident signs of dehydration and his serum sodium level was alarming testifying a delayed consultation. In fact, the situation may be more serious when hypernatraemia is manifested by only weight loss or a nonspecific symptom such as fever [7]. In these cases, there is also a risk of diagnostic delay even if the consultation is early especially when the clinician is not aware of this entity. The pathophysiology of hypernatraemic dehydration clearly identified. However, it seems that it may result from inadequate intakes of breast milk by lack of experience of primiparous mothers $[8,9]$. The sodium concentration of breast milk is high at birth and decreases progressively over the subsequent days [10]. Indeed, efficient sucking is a key mechanism that allows the transformation of colostrum into transitional milk and subsequently into mature milk containing less sodium. Galipeau et al. had demonstrated that also breastfeeding frequency during the first days of life influences breast milk sodium concentration and that breastfeeding every 2 to 3 hours is suitable for a safe decrease in sodium concentration [9]. Other risk factors for hypernatraemia such as gestational diabetes and maternal medication have been reported in the literature $[9,11]$. For our patient, the mother was primiparous and probably not paying attention to feeding frequency and duration. For management, breastfeeding should be resumed within few days. The severity of the disease should not discourage breastfeeding, which is the most appropriate for the neonate and mother health. This case highlights the importance of recognizing the risk of hypernatremia in breastfed newborns. It is a condition that can be serious and should be prevented by early and adequate breastfeeding and should never discourage it.

\section{Conclusion}

Hypernatraemic dehydration remains rare when breastfeeding is well adapted to the needs of the newborn. It should be prevented by precocious breastfeeding within the first hour after birth. Mothers, especially primiparas, should be aware about the necessity of frequent breastfeeding and checking the volume of breast milk and the weight gain of the baby. In the situation of dehydration, breastfeeding maternal should never be stopped definitively but temporarily replaced until it acquires its final composition.

\section{Conflicts of Interest}

No conflict of interest.

\section{Acknowledgement}

This research did not receive any specific grant from funding agencies in the public, commercial, or not-for-profit sectors.

\section{References}

1. Moritz ML, Ayus JC (2005) Preventing neurological complications from dysnatremias in children. Pediatr Nephrol 20: 1687-1700.

2. Moritz ML, Ayus JC (1999) The changing pattern of hypernatremia in hospitalized children. Pediatrics 104: 435-439.

3. Haycock GB (2006) Hypernatraemia : diagnosis and management. Arch Dis Child 91: 8-13.

4. Strachan SR, Morris LF (2017) Management of severe dehydration. J Intensive Care Soc 18: 251-255.

5. Oddie S, Richmond S, Coulthard M (2001) Hypernatremic dehydration and breast-feeding: a population study. Arch Dis Child 85: 318-320.

6. Rand SE, Kolberg A (2001) Neonatal hypernatremic dehydration secondary to lactation failure. J Am Board Fam Pract 14: 155-158.

7. Livingstone $\mathrm{VH}$, Willis $\mathrm{CE}$, Abdel-Wareth LO, Thiessen P, Lockitch $\mathrm{G}$ (2000) Neonatal hypernatremic dehydration associated with breastfeeding malnutrition: A retrospective survey. Can Med Assoc J 162: 647-652.

8. Rand SE, Kolberg A (2001) Neonatal hypernatremic dehydration secondary to lactation failure. J Am Board Fam Pract 14: 155-158.

9. Galipeau R, Goulet C, Chagnon M (2012) Infant and Maternal Factors Influencing Breastmilk Sodium Among Primiparous Mothers. Breastfed Med 7: 290-294.

10. McManaman JL, Neville MC (2003) Mammary physiology and milk secretion. Adv Drug Deliv Rev 55: 629-641.

11. Caglar MK, Ozer I, Altugan FS (2006) Risk factors for excess weight loss and hypernatremia in exclusively breastfed infants. Braz J Med Biol Res 39: 539-544. 